\title{
ANALISA PENGERASAN PERMUKAAN BUSHING S45C DENGAN METODE QUENCHING MEDIA CELUP OLI MENGUNAKAN MESIN INDUKSI DAN TEMPERING MESIN FURNACE
}

\author{
Moh Hendri Priyono ${ }^{1}$, Helmy Purwanto ${ }^{2}$ dan Muhammad Dzulfikar ${ }^{2}$ \\ ${ }^{1}$ Mahasiswa Jurusan Teknik Mesin, Fakultas Teknik, Universitas Wahid Hasyim \\ ${ }^{2}$ Dosen Jurusan Teknik Mesin, Fakultas Teknik, Universitas Wahid Hasyim \\ JL.Menoreh Tengah X/ 22, Semarang 50236, Indonesia. \\ *Email: ahendri810@Gmail.com
}

\begin{abstract}
ABSTRAK
Pengerasan permukaan dapat dilakukan dengan metode quenching menggunakan mesin induksi. Tujuan penelitian ini adalah untuk menganalisa kekerasan dan setruktur mikro baja S45C sebagai pengganti bushing bulldozer. Baja S45C dipanaskan dengan menggunakan mesin induksi pada temperatur $800,850,900^{\circ} \mathrm{C}$ dengan variasi koil 2 dan 3 lilitan, serta dicelup dengan media oli dan dilakukan tempering pada suhu $300^{\circ} \mathrm{C}$ selama 2 menit menggunakan mesin furnace. Hasil pengujian raw material memperlihatkan nilai kekerasn rata-rata 12 HRC dengan setruktur mikro ferit dan perlit. Setalah dilakukan qunching menggunakan mesin induksi dengan koil 2 lilitan dan 3 lilitan kekerasannya naik secara signifikan menjadi 54HRC dengan fasa setruktur mikro ferit dan matrensit. Setelah dilakukan tempering menggunakan mesin furnace kekeranya menurun 4-5 HRC dengan fasa setruktur mikro ferit dan matrensi temper.
\end{abstract}

Kata kunci: pengerasan permukaan, kekerasan, struktur mikro

\section{PENDAHULUAN}

Perkembangan industri permesinan dan konstruksi memacu perkembangan teknologi pembuatan material dasar logam seperti baja. Baja yang banyak digunakan harus berkualitas tinggi. Contohnya pada bushing.

Bushing bulldozer merupakan salah satu komponen pada sistem undercarriage yang mendapatkan beban impact berupa hentakan dan gesekan dengan teeth sproket dan pin (Anonimus, 2006). Sehingga karakteristik bushing harus mampu menerima beban dan ketahanan aus yang baik. Proses perlakuan panas (heat treatment) adalah salah satu rekayasa material untuk mengubah struktur logam dengan cara memanaskan spesimen dengan waktu tertentu.

Menurut Ismail dkk, (2015) pemanas induksi merupakan salah satu proses rekayasa material menggunakan metode induksi elektromagnetik. Arus eddy yang dihasilkan dalam logam menyebabkan pemanasan pada logam. Pemanas induksi dapat digunakan dalam berbagai fungsi, antara lain pengerasan permukaan, peleburan logam, pengelasan, dan pemanasan pada temperatur yang diinginkan.

Menurut (Miftahudin, 2012) heat treatmen dilakukan dengan banyak cara, misalnya pemanasan sampai suhu dan kecepatan tertentu, mempertahan kan untuk waktu tertentu sehingga temperaturnya merata, lalu didinginkan dengan media pendingin. Quenchtemper campuran oli dan solar membentuk fasa martensit temper yang lebih menyebar dibanding dengan menggunakan oli (Palupi, 2016), dan Quench-temper campuran oli dan air membentuk fasa martensit temper dan ferit (Astrini, 2016), sedangakan Quench-temper dengan menggunakan air membentuk fasa bainit dan martensit halus (Handoyo,2015).

Untuk mendapatkan kekerasan yang baik maka pada saat pemanasan harus mencapai struktur austenit, karena hanya austenit yang dapat bertransformasi menjadi martensit. Jika pada saat pemanasan masih terdapat struktur lain maka setelah di quench akan diperoleh struktur yang tidak seluruhnya terdiri dari martensit. Bila struktur lain itu bersifat lunak, misalnya ferit maka tentunya kekerasan yang tercapai juga tidak akan maksimum (Purwanto, 2011). Pada baja yang selesai di quenching terdapat tegangan sisa dan rapuh (Karmin, 2009). Untuk menghasilkan suatu produk yang menuntut keuletan dan tahan terhadap gesekan perlu dilakukan pemanasan ulang atau tempering. Tujuan penemperan adalah untuk meningkatkan keuletan dan mengurangi kerapuhan atau kekerasan dari logam (Murtiono, 2012), tempering dapat menurunkan kekerasan baja hasil quenching 
menjadi ulet (Bayuseno, 2015)

Tujuan penelitian ini adalah untuk menganalisa kekerasan dan setruktur mikro baja S45C sebagai pengganti bushing bulldozer dengan menggunakan metode quenching menggunakan alat pemanas induksi dan tempering menggunakan mesin furnace.

\section{METODE PENELITIAN}

Alat yang Digunakan yaitu Pemanas Induksi, Mesin bubut, Alat uji struktur mikro, Alat uji kekerasan, Mesin Furnace, Peralatan Kerja Bangku dan Alat ukur .

Bahan yang diuji Bushing bulldozer dan Baja S45C sebagai material pengganti.

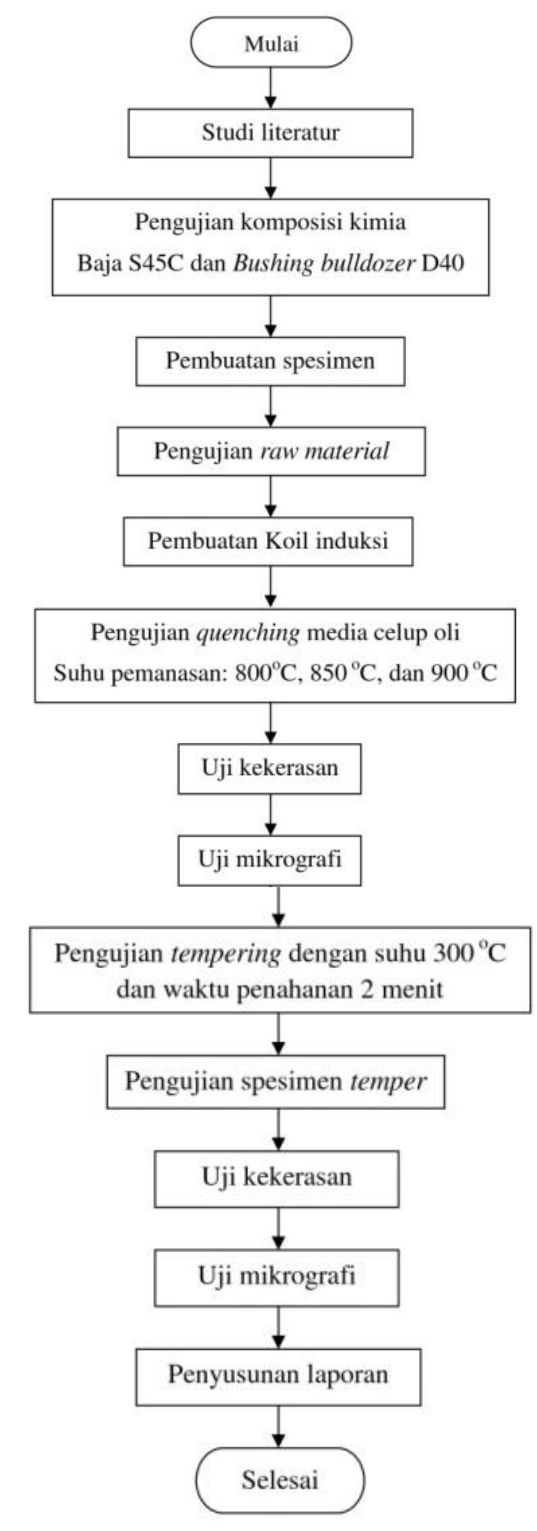

Gambar 1 diagram alir penelitian

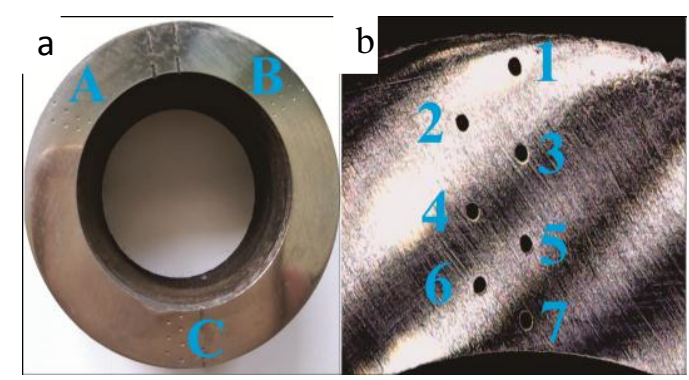

Gambar 2. Pengambilan data uji kekerasan (a). Tiga kelompok data kekerasan (b). Detail kelompok

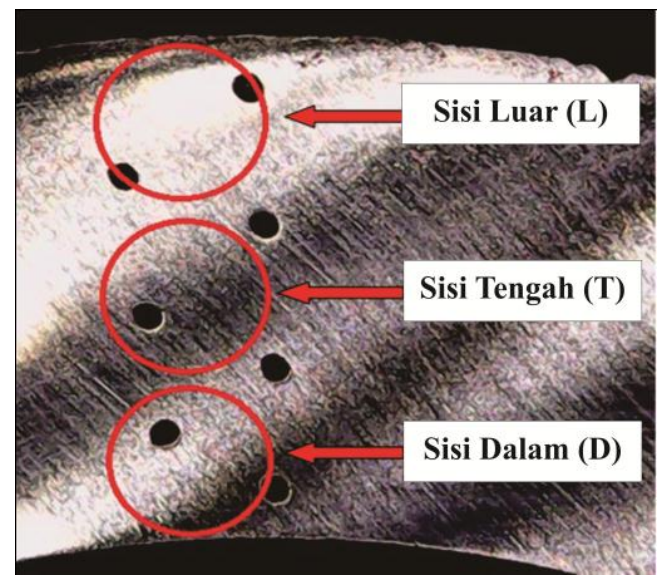

\section{Gambar 3. Pengambilan data struktur mikro}

Pada penelitian kali ini ada 3 prosedur, yaitu dari mulai tahap awal penelitian, proses pelaksanaan penelitian kemudian proses pembuatan spesimen dan proses pengujian.

Parameter pengujian yaitu perlakuan panas quenching menggunakan pemanas induksi variasi koil 2 dan 3 lilitan dengan suhu $800^{\circ} \mathrm{C}$, $850^{\circ} \mathrm{C}$ dan $900^{\circ} \mathrm{C}$ media celup oli, sementara untuk tempering menggunakan mesin furnace dengan suhu $300^{\circ} \mathrm{C}$ dengan waktu penahanan 2 menit.

\section{HASIL DAN PEMBAHASAN}

Uji kekerasan Bushing bulldozer D40

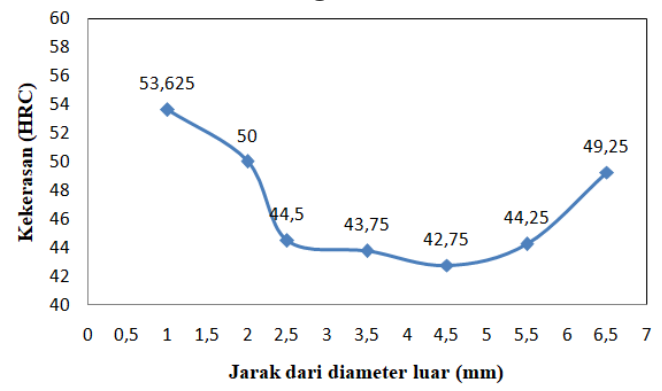

Gambar 4 Grafik kekerasan material bushing bulldozer D40 
Pada Gambar 4 dapat dilihat bahwa nilai kekerasan tertinggi didapat di posisi 1 diameter luar yaitu dengan nilai kekerasan 53,62 HRC, sementara untuk kekerasan paling rendah berada pada diameter tengah yaitu dengan nilai kekerasan 42,75 HRC dan naik kembali nilai kekerasannya diameter dalam.

Hasil pengujian kekerasan baja $\mathrm{S45C}$ setelah quenching

A. Baja S45C quenching koil 2 lilitan

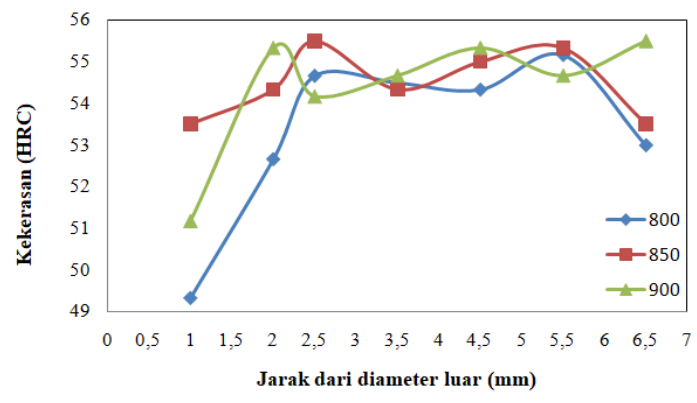

Gambar 5 Grafik kekerasan setelah hardening menggunakan koil 2 lilitan

Gambar 5 dapat dilihat hasil kekerasan setelah dilakukan perlakuan quenching kekerasannya mengalami kenaikan secara signifikan dari $10 \mathrm{HRC}$ menjadi rata -rata 55 HRC. Pada koil 2 lilitan spesimen temperatur $800^{\circ} \mathrm{C}$ terjadi kenaikan sampai tertinggi pada titik 6 sebesar 55,16 HRC. Pada pengerasan spesimen temperatur $850^{\circ} \mathrm{C}$ di titik 3 dengan nilai kekerasan tertinggi 55,5 HRC,. Pada pengerasan spesimen temperatur $900^{\circ} \mathrm{C}$ pada memiliki kekerasan tertinggi sebesar 55,5 HRC.

B. Baja S45C quenching koil 3 lilitan

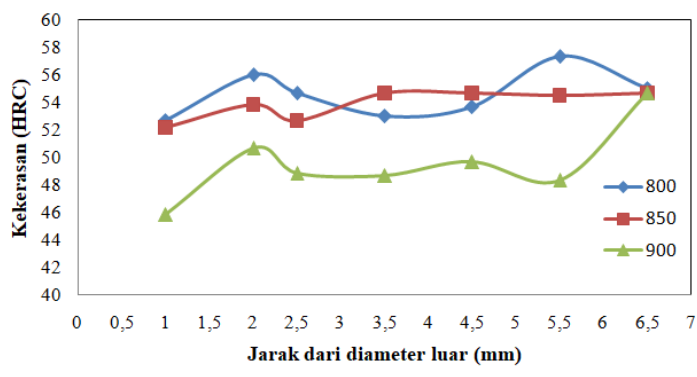

Gambar. 6 Grafik kekerasan setelah hardening menggunakan koil 3 lilitan

Berdasarkan Gambar 6 dapat dilihat hasil kekerasan setelah dilakukan perlakuan quenching pada koil 3 lilitan pada spesimen temperatur $800^{\circ} \mathrm{C}$ dan pada spesimen temperatur $850^{\circ} \mathrm{C}$ memiliki kekerasan yang hampir sama. Pada pengerasan spesimen temperatur $900^{\circ} \mathrm{C}$ di titik pertama memiliki nilai kekerasan paling rendah sebesar 45,8 HRC, dan kekerasan tertinggi sebesar 54,6 HRC.

\section{Hasil pengujian kekerasan baja S45C setelah tempering}

A. Tempering pasca quenching pemanasan $900^{\circ} \mathrm{C}$ pada koil 2 lilitan.

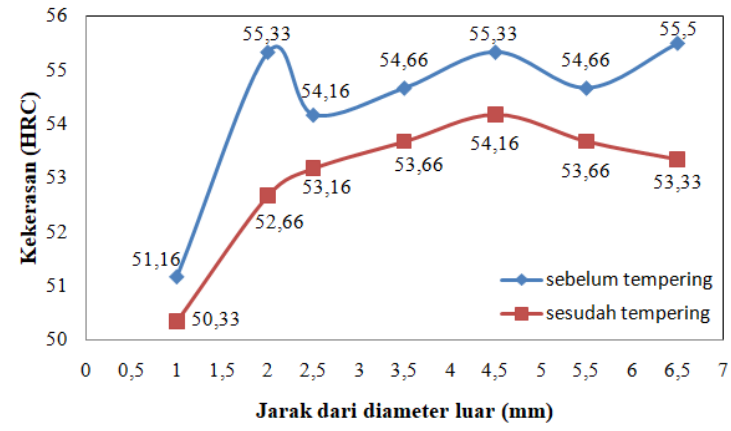

Gambar 7 Grafik perbandingan kekerasan sesudah quenching koil 2 lilitan dan sesudah tempering

Dari perbandingan kekerasan sebelum dan sesudah dilakukan tempering pada Gambar 7 dapat dilihat bahwa nilai kekerasan mengalami penurunan yaitu di titik 2 diameter luar dari 55,33 HRC menjadi 52,66 HRC, titik 5 diameter tengah dari 55,33 HRC menjadi 54,16 HRC, dan titik 7 diameter dalam dari 55,5 HRC menjadi 5,33 HRC.

B. Tempering pasca quenching pemanasan $900^{\circ} \mathrm{C}$ pada koil 3 lilitan.

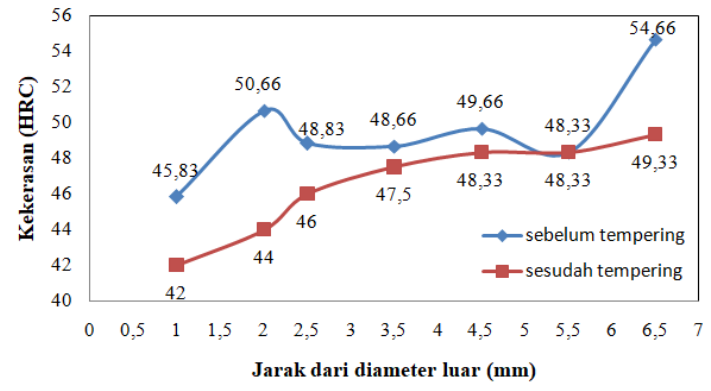

Gambar 8 Grafik perbandingan hasil kekerasan sesudah quenching koil 3 lilitan dan tempering

Dari perbandingan kekerasan sebelum dan sesudah dilakukan tempering pada Gambar 8 
dapat dilihat bahwa nilai kekerasan mengalami penurunan yaitu dari 50,6 HRC menjadi 44 HRC, titik 4 diameter tengah dari 48,33 HRC menjadi 47,5 HRC, dan diameter dalam dari 54,66 HRC menjadi 49.33 HRC.

\section{Hasil pengujian foto mikro}

A. Hasil pengujian foto mikro bushing bulldozer

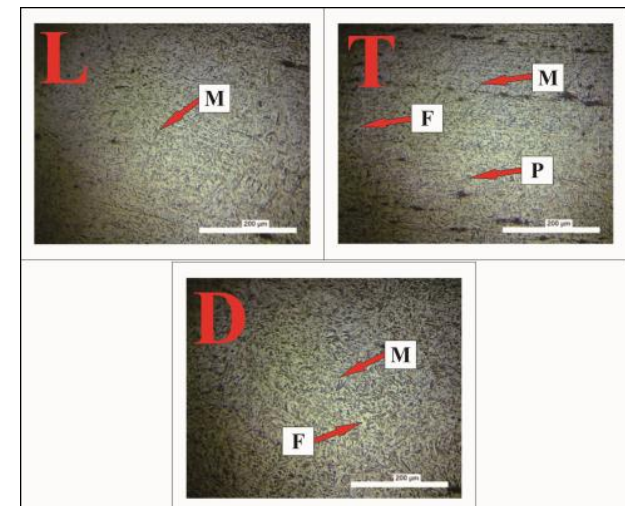

Gambar 9 Hasil struktur mikro bushing bulldozer (L)diameter luar, (T) diameter tengah, (D) diameter dalam

Dari Gambar 9 dapt disimpulkan bahwa pada diameter luar dan diameter dalam terlihat banyak terbentuk struktur martensit (M) dengan nilai kekerasan 52,67 HRC. Pada diameter tengah masih terdapat struktur ferit $(\mathrm{F})$ dan perlit (P) karena kekerasan pada diameter tengah 49,33 HRC. Lebih rendah daripada diameter luar dan diameter dalam dengan nilai kekerasan 43,67 HRC.

B. Hasil foto mikro baja S45C setelah quenching

1. foto mikro baja $\mathrm{S} 45 \mathrm{C}$ setelah quenching dengan suhu $900{ }^{\circ} \mathrm{C}$ koil 2 lilitan

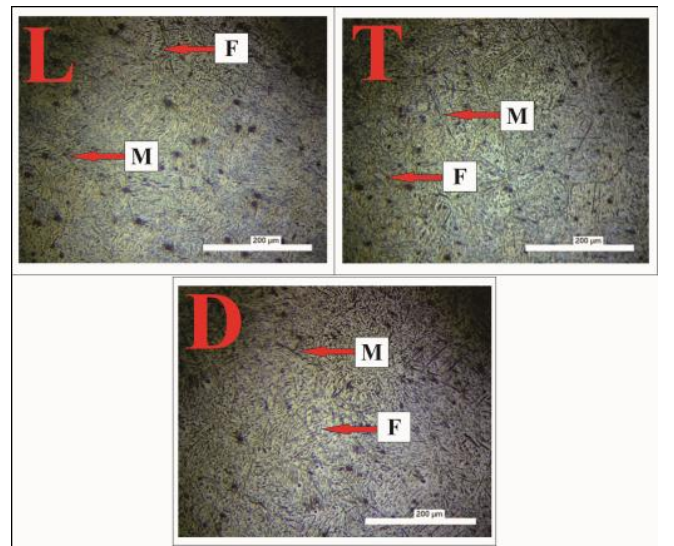

Gambar 10 Setruktur mikro baja S45C quenching dengan suhu $900{ }^{\circ} \mathrm{C}$ menggunakan

\section{koil 2 lilitan (L) diameter luar, $T$ diameter} tengah dan (D) diameter dalam

Dari hasil Gambar 10 quenching dengan suhu $900{ }^{\circ} \mathrm{C}$ menggunakan koil 2 lilitan (L) diameter luar, (T) Diameter tengah dan (D) Diameter dalam. Pada ketiga titik yang dilakukan uji struktur mikro tersebut rata-rata terbentuk fasa martensit. Menurut (Saifudin dan Malau, 2014) akibat quenching dengan oli menyebabkan karbon tidak dapat berdifusi keluar dan tertangakap didalam larutan jenuh sehingga terbentuk fase martensit dalam bentuk BCT dengan tranformasi geser. Besi yang berada pada fase martensit akan memiliki sifat yang kuat dan keras, akan tetapi besi ini juga bersifat getas dan rapuh.

2. Foto mikro baja S45C setelah quenching dengan suhu $900{ }^{\circ} \mathrm{C}$ koil 3 lilitan

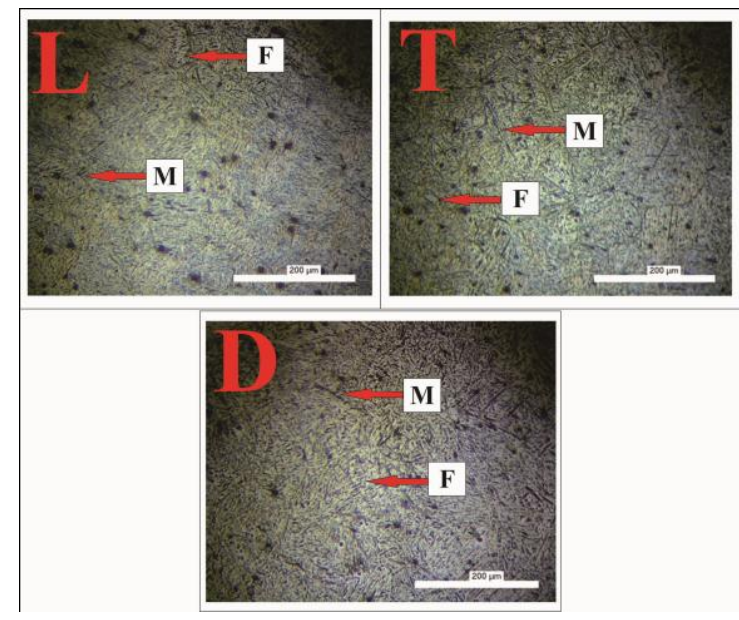

Gambar 11 Setruktur mikro baja S45C quenching dengan suhu $900{ }^{\circ} \mathrm{C}$ menggunakan koil 3 lilitan (L) diameter luar, (T) diameter tengah dan (D) diameter dalam

Dari hasil Gambar 11 setruktur mikro baja S45C quenching dengan suhu $900^{\circ} \mathrm{C}$ ${ }^{\circ} \mathrm{C}$ menggunakan koil 3 lilitan pada Gambar (L) diameter luar terlihat masih berbentuk fasa ferit dan martensit tidak begitu merata. Menurut (Haryadi, 2005) apabila semakin besar warna putih pada suatu setruktur mikro baja, maka semakin banyak ferit yang terbentuk berarti bahwa material tersebut semakin lunak dan ulet, dan ditunjukkan dengan nilai kekerasan 45,83 HRC. Pada Gambar (T) diameter tengah fasanya masih sama ferit dan martensit ditunjukkan dengan nilai kekerasan 48,83 HRC. Sedangkan pada Gambar (D) diameter dalam terlihat fase martensitnya lebih mereta dan 
rapar dibandingkan diameter luar dan tengah, ditunjukkan dengan nilai kekerasan 54,66 HRC.

C. Baja S45C setelah di tempering

1. Tempering pasca quenching suhu pemanasan $900^{\circ} \mathrm{C}$ koil 2 lilitan

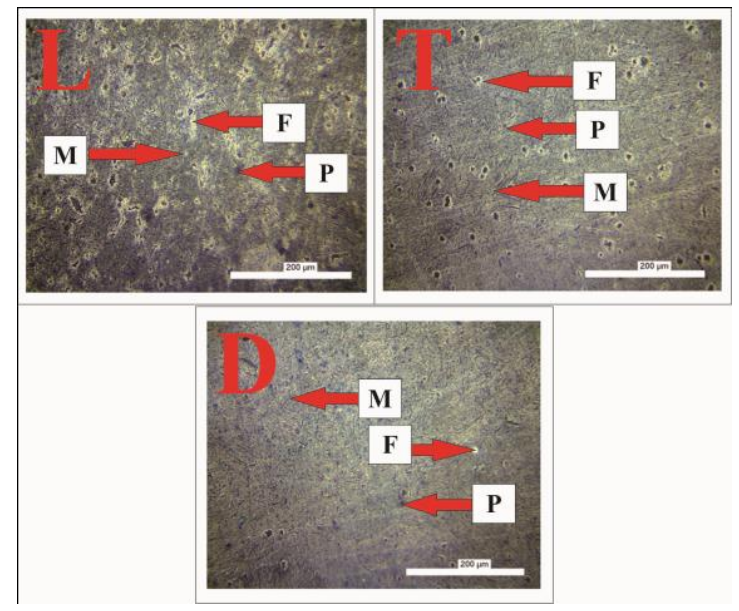

Gambar 12 Setruktur mikro baja S45C tempering pasca quenching $900{ }^{\circ} \mathrm{C}$ koil 2 lilitan (L) diameter luar, (T). Diameter tengah dan (D). Diameter dalam.

Dari hasil Gambar 12 setruktur mikro baja S45C pasca quenching $900{ }^{\circ} \mathrm{C}$ menggunakan koil 2 lilitan (L) diameter luar, (T) diameter tengah dan (D) diameter dalam. Pada ketiga titik yang dilakukan uji struktur mikro tersebut rata-rata masih terbentuk fasa martensit namun tidak terlalu dominan seperti setelah quenching. Menurut Amstead, (1997) Baja karbon dan baja paduan medium pada saat di tempering kekerasannya akan menurun akibat adanya penguraian martensit tetragonal menjadi martensit temper dan karbida Umumnya makin tinggi temperatur tempering, makin besar penurunan kekerasan dan makin besar pula peningkatan keuletan dan ketangguhannya. Oleh karena itu dengan munculnya martensit temper yang banyak akan menjadikan struktur material yang stabil dan tidak terlalu keras seperti setelah di quenching. Dari ketiga diameter yang paling dominan hampir menyeluruh terbentuk fasa martensit yaitu pada diameter tengah yang mempunyai nilai kekerasan 54,16 HRC. Sedangkan pada diameter luar dan diameter dalam masih ada fasa ferit dan perlit yang memiliki nilai kekerasan 50,33 HRC dan 53,33 HRC

2. Tempering pasca quenching suhu pemanasan $900^{\circ} \mathrm{C}$ koil 3 lilitan

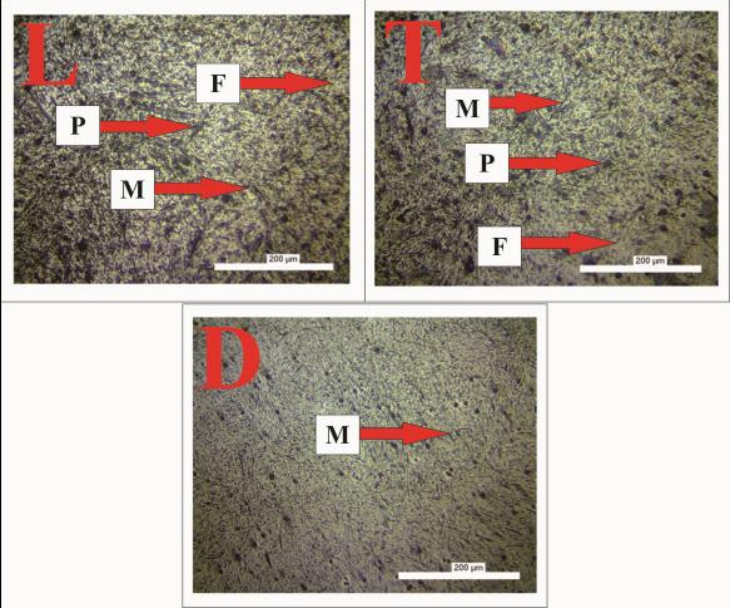

Gambar 13 Setruktur mikro baja S45C tempering pasca quenching dengan suhu 900 ${ }^{\circ} \mathrm{C}$ koil 3 lilitan (L) diameter luar, (T) diameter tengah dan (D) diameter dalam

Dari hasil Gambar 13 setruktur mikro baja S45C tempering pasca quenching dengan suhu $900{ }^{\circ} \mathrm{C}$ menggunakan koil 3 lilitan (L) diameter luar, (T) diameter tengah dan (D) Diameter dalam. Pada Gambar (L) diameter luar terlihat masih berbentuk fasa ferit dan martensit tidak begitu merata dan ditunjukkan dengan nilai kekerasan 42 HRC. Pada Gambar (T) diameter tengah fasanya masih sama ferit dan martensit tetapi lebih banyak dibandingkan Gambar (L) ditunjukkan dengan nilai kekerasan 46 HRC. Sedangkan pada Gambar (D) diameter dalam terlihat fase martensit temper lebih mereta dan rapat dibandingkan diameter luar dan tengah, ditunjukkan dengan nilai kekerasan 49,33 HRC.

\section{KESIMPULAN}

Beberapa kesimpulan yang dapat diambil dari penelitian ini adalah:

1. Pada bushing bulldozer D40 memiliki ratarata nilai kekerasan pada diameter luar 52,67 HRC struktur martensit, tengah 43,67 HRC struktur martensit, perlit, dan ferit sementara pada diameter dalam 49,33 HRC struktur martensit dan ferit.

2. Kekerasan baja S45C setelah di quenching menggunakan koil 2 lilitan terendah 51,16 HRC dan tertinggi 55,5 HRC terletak pada diameter dalam, sedangkan struktur mikronya berupa fasa martensit. Sedangkan quenching dengan koil 3 lilitan terendah 45,83 HRC dan tertinggi 54,66 HRC terletak pada diameter dalam struktur mikronya berupa fasa ferit dan martensit karena proses quenching 
3. Kekerasan baja S45C setelah ditempering pasca quenching koil 2 lilitan terendah 50,33 HRC dan tertinggi 53,16 HRC. Pada Kekerasan baja S45C setelah ditempering pasca quenching menggunakan koil 3 lilitan terendah 42 HRC dan tertinggi 49,33 HRC. Kekerasan baja S45C setelah dilakukan tempering pada suhu $300^{\circ} \mathrm{C}$ dengan waktu penahanan 2 menit kekerasnya menurun rata-rata 4 HRC. Disebabkan karena fasa matensit menjadi martensit temper.

\section{DAFTAR PUTAKA}

Amstead, B.H dan philip, F. Oswawald., 1997., Teknologi Mekanik Jilid 1, Erlangga. Jakarta.

Anonimous. 2006. Modul mechanic development, Sistem final drive and undercarriage. PT. United Tractors. Tbk

Astrini, I, R. 2016. Pengaruh Heat Treatment Dengan Variasi Media Quenching Air Dan Oli Terhadap Struktur Mikro Dan Nilai Kekerasan Baja Pegas Daun Aisi 6135. Universitas Lampung. Skripsi Hal. 1-68, Juni 2016.

Bayuseno, A, P. Yohana, E. Dzulfikar, M. Prasetyo, D, I. Khafidh, M. dan Ismail, R. 2014. Pengaruh Tempering Menggunakan Pemanas Induksi Terhadap Nilai Kekerasan Dan Struktur Mikro Material Baja St-60 Pasca Quenching. Universitas Diponegoro. SNTMUT - 2014.

Handoyo, Y. 2015. Pengaruh Quenching Dan Tempering Pada Baja Jis Grade S45C Terhadap Sifat Mekanis Dan Struktur Mikro Crankshaft. Universitas Islam 45 Bekasi. Jurnal Imiah Teknik Mesin, Vol. 3, No.2 Agustus 2015

Haryadi., 2005., Pengaruh Suhu Tempering terhadap Kekerasan Struktur Mikro dan Kekuatan Tarik pada Baja K-460. Jurnal Teknik Mesin Rotasi. Vol. 7.No. 3.pp 1-10.

Ismail. R., Aprilitama.N.R., dan Sugiyanto. 2015. Pengamatan Struktur Mikro Dan Kekerasan Pada Roda Gigi Pasca Pengerasan Permukaan Menggunakan Pemanas Induksi. Universitas Diponegoro. junal Rotasi Teknik Mesin - Vol. 17, No. 3, Juli 2015: 145-152.

Karmin., 2009., Pengendalian Proses Pengerasn Baja Degan Metode Quenching., Junal Austenit. Politeknik Negeri Sriwijaya Palembang. Vol. 1.No. 2 Oktober 2009.

Miftahudin. 2012. Pengaruh temper dengan Quench Media Oli Mesran SAE 20W- 50 Terhadap Karakteristik Medium Carbon Steel. Skripsi. Pendidikan Teknik Mesin Fakultas Teknik Universitas Negeri Semarang. Semarang

Murtiono. A., 2012., "Pengaruh quenching dan tempering terhadap kekerasan dan kekuatan tarik serta setruktur mikro baja karbon sedang untuk mata pisau pemanen sawit". Universitas Sumatera Utara., Jurnal edinamis., Volume II, No.2. September 2012.

Palupi, O, B. Karo, P, K. dan Supriyatna, Y, I. 2016. Pengaruh Heat Treatment denganVariasi Media Quenching Oli dan Solar terhadap Struktur Mikro dan Nilai Kekerasan Baja Pegas Daun AISI 6135. Universitas Lampung. Jurnal Teori dan Aplikasi Fisika Vol. 4, No.02, Juli 2016.

Purwanto. H., 2011., Analisa quenching pada baja karbon rendah dengan media solar., Universitas Wahid Hasyim., Jurnal Ilmiah Momentum., Vol. 7, No 1, April 2011 : 3640.

Saifudin Dan Malau., 2014., Karaktrisasi Mekanis Dan Fisis Pada Perlakuan Tool Steel HSS (High Speed Steel) Dengan Teknik Perlakuan Panas., Prosiding SEMNAS Rekayasa Material Sistem Manufaktur Dan Energi., Universitas Muhamadiyah Malang. 